\title{
Ancient Micro-Scale Hydraulic Elements in Sri Lanka: Functionality and Interpretations of Dedigama Eth Pahana.
}

\author{
C. Jayawardana and K. Peiris
}

\begin{abstract}
Despite well established scientific studies and findings on ancient macro scale hydraulic structures in Sri Lanka, the studies on ancient micro-scale hydraulic structures are very limited. The operational features of the article known as Dedigama 'Eth Pahana' indicates the automatic control of a fluid flow, which has not been subjected to any scientific analysis so far. Although this is a single object, it gives a prime opportunity to investigate the operation and formulation of theoretical background for such operation, thus giving some insight of micro scale hydraulic elements. This paper is presented in that context, with further review of alternative possibilities on the application of the subject item.
\end{abstract}

Key words: eth pahana, micro scale hydraulic elements, makara thorana

\section{Introduction}

Sri Lanka possesses a well established macro scale hydraulic structural system developed approximately from 3 rd century $B C$ to $12^{\text {th }}$ century AD. This consists of reservoirs, distribution canals and most importantly the water flow controlling devices, known as bisokotuwa. The functionality of bisokotuwa was mathematically explored by Peiris et al [1] and a working model constructed in line with the same mathematical explanation is now available in Polonnaruwa gallery at Colombo National Museum.

A vast amount of scientific literature is available regarding the above macro scale hydraulic bodies, but the investigations and scientific literature relating to ancient Sri Lankan micro scale hydraulic equipment are very rare. This may be due to the fact that the comparative scarcity of such equipment. A good example of this is to be found in the two lamps found in a stupa at Dedigama, and now available in Polonnaruwa gallery at Colombo National Museum. This is generally known as eth pahana, meaning the lamp resembles the figure of an elephant, among the concerned circles. The same terminology will be used in this paper also despite the fact that the functionality of this object might be otherwise. Succeeding chapters will be dedicated to identifying the working principle of eth pahana in hydraulic perspectives and offer some alternative interpretations of its functionality.

\section{Eth pahana, A General Description}

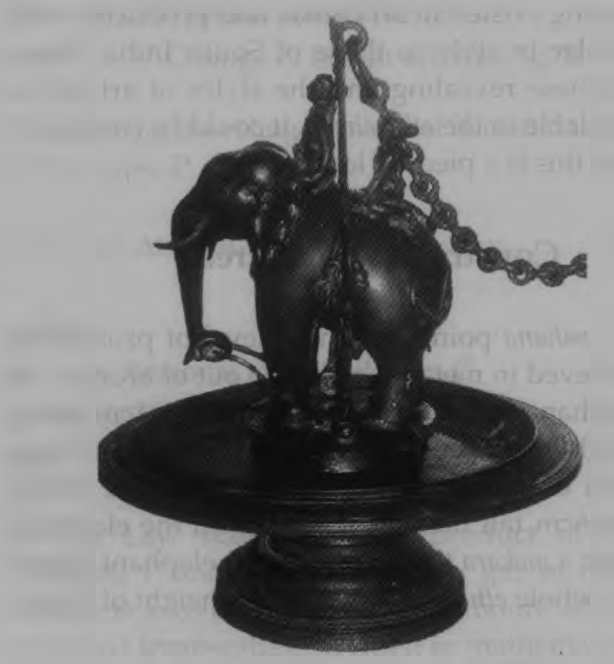

Fig. 1: Eth pahana

This was excavated from upper relic chamber of Suthiyaghara stupa at Dedigama in 1951. Paranavithana [2] quoting work of H.W Codrington in Ceylon Journal of Science, Part G, Vol.2, confirms present day Dedigama is the ancient area known as Punkhagama, which was the birth place of king Parakramabahu 1 [1153-1186 AD]. The stupa was identified as the one constructed by the same king to mark his

Eng. C Jayawardana B.Sc (Eng)Hons, MTech, MA, MIET, MIE (Sri Lanka), C.Eng, presently Project Manager, Cruicksharks Ceylon Pvt. Ltd. Katunayaka.

Eng. K Peiris B.Sc (Eng), MPhil, MA, MIE (Sri lanka), C.Eng, presently Research Engineer, National Engineering Rescarch and Developinent Centre [NERD], Ekala. 
birth place and hence the construction period of the eth pahana is also dated to the reign of king Parakramabahu I, $12^{\text {th }}$ century BC. Gunawardana [3] also notes that the construction of eth pahana could be dated in the $12^{\text {th }}$ century AD with a fair degree of confidence.

The construction material of eth pahana has been identified as bronze, which was a common material for many artifacts in this period of time according to Coomaraswamy [4] and Godakumbura [5]. The origination source of this article is not solidly established. But there are some supporting evidences to conclude that by $12^{\text {th }}$ century AD, Sri Lankan artists possessed a significant skill in bronze casting technology. Rao [6] quotes from a publication called Kamikagama which sites treatises of Simhaladesa, present Sri Lanka regarding the bronze work and Basham [7] highlights an important school of bronze casting existed in Sri Lanka, and produced work similar in style to those of South India. Based on these revealing and the styles of art works available in the eth pahana, it could be concluded that this is a piece of local work.

\section{Construction Features}

Eth pahana points to a high level of proficiency achieved in metallurgy, made out of bronze. An elephant figure having a width of $6.1 \mathrm{~cm}$ and a height of $12.6 \mathrm{~cm}$ is placed on top of a dish base with diameter of $23 \mathrm{~cm}$ and a height of $8.5 \mathrm{~cm}$. A $4.6 \mathrm{~cm}$ tall mahout is placed on the elephant. With a makara throna around the elephant figure, the whole eth pahana stands to a height of $25 \mathrm{~cm}$.

It is evident that main elements have been produced in several parts before they were assembled together. It basically consists of a base, an elephant figure and a hanging arrangement. An internal cavity inside the elephant figure serves as a reservoir for oil. The production of the elephant figure itself presents a rather complicated technical problem since it had to be cast with an inner chamber for oil, with inlet pipe through its foreleg and an outlet orifice through genital organ. The elephant figure filled with oil was to mount on the base. There is a special provision to lock the elephant figure to the base, in order to avoid any relative movements. The base is fixed with a flame creeper which is decorated with a makara head, at the point of connection to the base. A chain, decorated with fine figures of dancers and drummers is attached to the flame creeper, and ended with a carving of a cobra head making. The whole assembly could be hanged.

\section{Operational Methodology}

Authors were not able to locate information regarding the internal structure of the elephant figure and hence a hypothetical cross sectional view had to be developed for analytical purposes. This is as shown in fig. 2 and will be used for the mathematical analysis of the following sequence of operations.

The elephant figure needs to be overturned and oil could be poured into the hole in its foreleg sole, which will consequently fill the reservoir, $\mathrm{R}$. Once this is correctly placed on the base, oil starts to flow from orifice, $\mathrm{O}$ as droplets. The rate of oil flow would have been greater than the rate of oil burned, thus making a resultant accumulation of oil in the container, $C$. The rising oil level will submerge the opening hole of pipe $\mathrm{P}$, at which point the oil flow through orifice ceases. This is perhaps the most noteworthy feature of this lamp as that the outflow of oil from the reservoir $\mathrm{R}$ to the lamp base was to use as the mean of automatic controlling of the oil level at the container C. Although Gunawardana [3] notes this operation was based on "hydrostatic principles", our understanding is that still hydro dynamic, principals are also applicable in explaining this sequence.

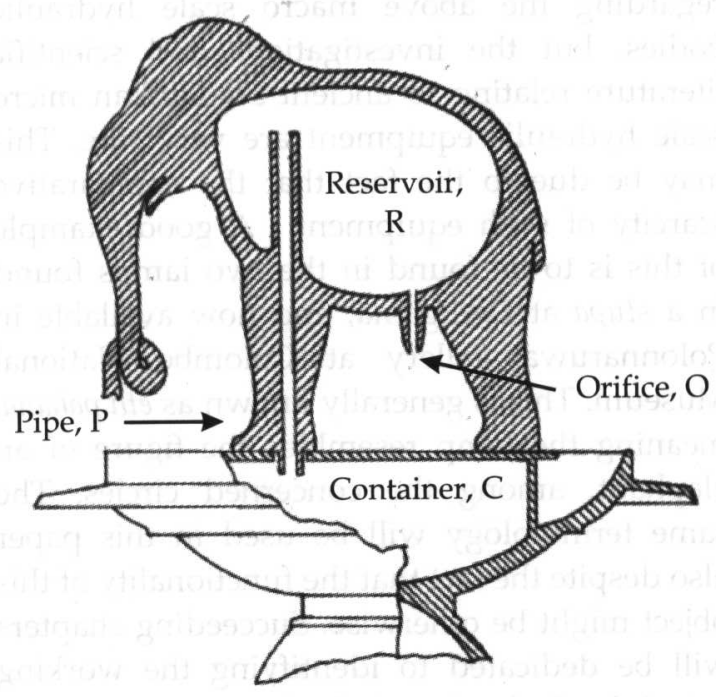

Fig.2: Hypothetical sketch of eth pahana

This sequence of events have been demonstrated and proved using the real lamp at Colombo National Museum. 


\section{Operational Analysis}

A simplified model was developed as fig. 3 for the analytical purposes.

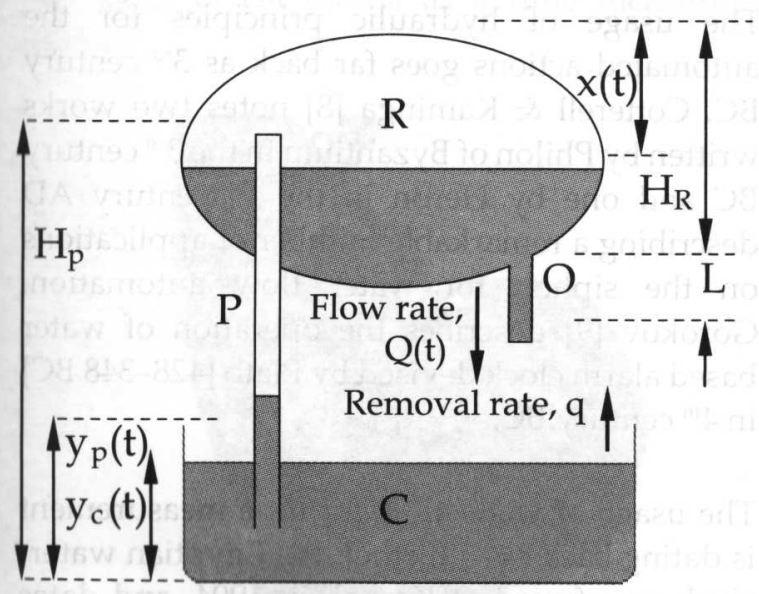

Fig. 3: Simplified model of eth pahana

$\mathrm{x}(\mathrm{t}) \quad=$ Height from top of $\mathrm{R}$ to oil surface

$\mathrm{H}_{\mathrm{R}}=$ Height from top of $\mathrm{R}$ to orifice $\mathrm{O}$

$\mathrm{L} \quad=$ Length of orifice $\mathrm{O}$

$\mathrm{Q}(\mathrm{t})=$ Oil flow rate through orifice $\mathrm{O}$

$\mathrm{q}=$ Oil removal rate from $\mathrm{C}$

$\mathrm{yc}_{\mathrm{c}}(\mathrm{t})=$ Height from bottom of $\mathrm{C}$ to oil surface

$y_{p}(t)=$ Height from bottom of $C$ to oil level inside $\mathrm{P}$

$\mathrm{H}_{\mathrm{p}}=$ Height from bottom of $\mathrm{C}$ to end of $\mathrm{P}$

From fig. 3, it is evident that only $x(t), y c(t), y p(t)$ and $Q(t)$ are the time variable parameters. $\Delta x, \Delta y c$, $\Delta y p$ and $\Delta Q$ will be treated as the incremental quantities of each these parameters within a time period of $\Delta \mathrm{t}$.

Considering the oil pressure at container $\mathrm{C}$ oil surface,

$P(t)=P a-[y p(t)-y c(t)] \cdot \rho g$

$\mathrm{P}(\mathrm{t}+\Delta \mathrm{t})=\mathrm{Pa}-\left[\left[\mathrm{yp}(\mathrm{t})-\mathrm{yc}_{\mathrm{c}}(\mathrm{t})\right]+[\Delta \mathrm{yp}-\Delta \mathrm{yc}]\right] \rho \mathrm{g}$

where,

$\mathrm{P}(\mathrm{t})=$ Pressure of air trapped in $\mathrm{R}$ at time $\mathrm{t}$

$\mathrm{Pa} \quad=$ Atmospheric pressure

$\rho \quad=$ Density of oil

g = Gravitational acceleration

Solving Eq.1 and Eq.2,

$\mathrm{P}(\mathrm{t}+\Delta \mathrm{t})=\mathrm{P}(\mathrm{t})-[\Delta \mathrm{yp}-\Delta \mathrm{yc}] \rho \mathrm{g}$
Therefore, after specifying initial conditions, an iterative process on these incremental quantities could be performed to find the time at which $\mathrm{P}(\mathrm{t}+\Delta \mathrm{t})=\mathrm{Pa}-\left[\mathrm{HR}_{\mathrm{R}} \mathrm{x}(\mathrm{t})+\mathrm{L}\right] \rho g$, where oil flow from orifice $\mathrm{O}$ will cease. The purpose of the below analysis is to develop a set of equations governing the incremental quantities $\Delta y p$ and $\Delta y c$. Solving of those equations is not considered under the scope of this paper.

Considering the relationship between flow rate through orifice $\mathrm{O}$ and volume change in reservoir $\mathrm{R}$, during time interval $\Delta \mathrm{t}$,

$\mathrm{Q}(\mathrm{t}) \cdot \Delta \mathrm{t}=[\mathrm{dV}(\mathrm{x}) / \mathrm{dx}] \cdot \Delta \mathrm{x}$

where,

$\mathrm{V}(\mathrm{x}) \quad=$ Volume of air trapped in reservoir $\mathrm{R}$

$\mathrm{Q}(\mathrm{t}) \quad=$ Flow rate at time $\mathrm{t}$

$\mathrm{dV}(\mathrm{x}) / \mathrm{dx}=$ Volume change of $\mathrm{V}(\mathrm{x})$

$\Delta \mathrm{x} \quad=$ Change of height $\mathrm{x}(\mathrm{t})$ during $\Delta \mathrm{t}$

Considering the rising of oil level in container, $\mathrm{C}$ and in pipe, $P$

$[Q(t)-q] \cdot \Delta t=\left[A_{c}-A_{p}\right] \cdot \Delta y_{c}+A_{p} \cdot \Delta y p$,

where

$\mathrm{q}=$ Removal rate of oil from $\mathrm{C}$

Ac = Oil surface area of $\mathrm{C}$

Ap $=$ Internal cross section area of $\mathrm{P}$

Boyle's Law states that the product of the pressure, $\mathrm{P}$ and volume, $\mathrm{V}$ for a gas in close system is a constant for a fixed amount of gas at a fixed temperature. Written in mathematical terms, this is $\mathrm{PV}=$ constant, hence $\mathrm{d}[\mathrm{PV}] / \mathrm{dt}=0$

Considering the air volume trapped inside reservoir, $\mathrm{R}$

$P(t)=P_{a}-\left[y p(t)-y_{c}(t)\right] \cdot \rho g$

$\mathrm{V}(\mathrm{t})=\mathrm{V}(\mathrm{x})+[\mathrm{Hp}-\mathrm{yp}(\mathrm{t})] \cdot \mathrm{A}_{\mathrm{p}}$

where,

$\mathrm{P}(\mathrm{t}) \quad=$ Pressure of air trapped in $\mathrm{R}$ at time $\mathrm{t}$

$\mathrm{V}(\mathrm{t})=$ Volume of air trapped in $\mathrm{R}$ at time $\mathrm{t}$

$\mathrm{Ap}_{\mathrm{p}} \quad=$ Internal cross area of pipe $\mathrm{P}$

$d[P(t) \cdot V(t) / d t]=0$ gives

$\left[\Delta \mathrm{yc}_{\mathrm{c}}-\Delta \mathrm{yp}\right]\left[\mathrm{V}(\mathrm{x})+[\mathrm{Hp}-\mathrm{yp}(\mathrm{t})] \mathrm{A}_{\mathrm{p}}\right]+[\mathrm{Pa}-\rho g[\mathrm{yp}(\mathrm{t})-$ $\mathrm{yc}(\mathrm{t})]\left[\mathrm{dV}(\mathrm{x}) / \mathrm{dx} . \Delta \mathrm{x}-\mathrm{Ap}_{\mathrm{p}} \Delta \mathrm{yp}\right]=0$ 
For a fluid flow through a pipe, the flow rate $\mathrm{dQ} / \mathrm{dt}$ is given by,

$$
\mathrm{dQ} / \mathrm{dt}=\Pi \mathrm{a}^{4} / 8 \eta(\Delta \mathrm{p} / \Delta \mathrm{l}+\rho \mathrm{g})
$$

where,

$$
\begin{array}{ll}
\mathrm{a} & =\text { internal cross section area of pipe } \\
\eta & =\text { Viscosity of the flowing fluid } \\
\Delta \mathrm{p} & =\text { Pressure difference at pipe ends } \\
\Delta \mathrm{l} & =\text { Length of pipe }
\end{array}
$$

applying to the oil flow through orifice $\mathrm{O}$,

$$
Q(t)=\Pi A_{o}{ }^{4} / 8 \eta\left[\left[P(t)+\left[H_{R}-x(t)\right] \cdot \rho g-P a\right] / L+\rho g\right] \ldots(7)
$$

By simplifying and solving the above Eq.4, Eq.5, Eq.6 and Eq.7 equations, the incremental quantities $\Delta y_{c}$ and $\Delta y_{p}$ could be solved in terms of $y_{p}(t), y_{c}(t), P(t), V(x)$, and dimensions. Then subjected to the iteration process, the time at which oil flow through orifice $\mathrm{O}$ ceases could be determined.

The forces at orifice $\mathrm{O}$ due to surface tension was not considered in the above equations as a special arrangement has been provided in the $e$ th pahana to minimize effects from surface tension on oil flow. The inner diameter of opening end of the orifice is enlarged to ensure the maximum amount of oil to be transferred to container $C$ from R. Same time, the inner diameter of the upper part of the orifice is thinner, in order to maintain the controllability of the oil flow. This arrangement is as shown in fig. 4 .

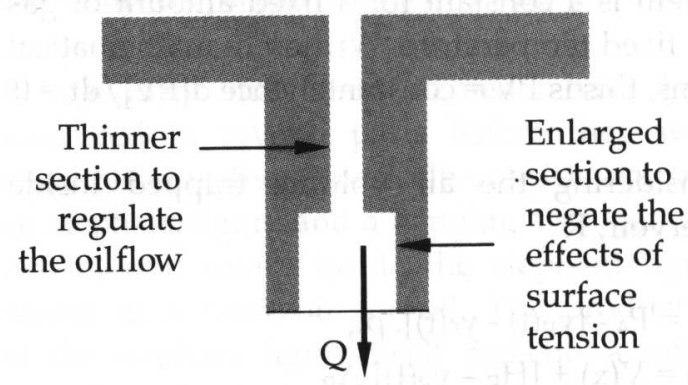

Fig. 4: Special arrangement at opening of the orifice $O$

\section{Alternative Application Possibilities}

It is recorded that soot and pieces of burnt wicks were in the oil container $C$ at the time of first finding. This prompted to identify eth pahana as a lamp and that identification continued to date. This identification has been supplemented by the findings of similar articles from India. Gunawardana [3] quoting the work of D.G Kelker in his book Lamps of India, notes seven similar lamps located in various parts of India.

The usage of hydraulic principles for the automated actions goes far back as $3^{\text {rd }}$ century BC. Cotterell \& Kaminga [8] notes two works written by Philon of Byzantium in the $3^{\text {rd }}$ century $B C$ and one by Heron in the $1^{\text {st }}$ century $A D$ describing a remarkable number of applications on the siphon for water flow automation. Gorokov [9] describes the operation of water based alarm clock devised by Plato [428-348 BC] in $4^{\text {th }}$ century BC.

The usage of water flow for time measurement is dating back even further. An Egyptian waterclock was found at Karnak in 1904, and dates from the reign of King Amenhotep III [1415-1380 $\mathrm{BC}$ ]. This was a tapered shape vessel, filled with water, which leaked out slowly from a small hole near the bottom. The time being indicated by the level of the water remaining within the vessel.

In the light of above, it is worthy to consider the possibilities of using eth pahana for alternative functionalities transcending its use as a lamp. This possibility is further emphasized by the fact that no special locations are available for placing the wicks for lighting in eth pahana. Present lamps as well as historical objects identified as oil lamps are equipped with such provision as unsupported wicks may be liable for dislocation during the course of lighting, and not serving its intended purpose. Another factor negating the functionality of eth pahana as a lamp is the method employed in filling the oil. Being the genital organ of the elephant, this may not be the ideal means to feed a lamp, which is a religiously venerable object.

Considering the process of initiating the lamp, a known amount of oil would be placed inside reservoir $R$, and container $C$. then the elephant figure would be placed in its attributed position. This initial oil volume defines the parameters $y_{c}(t=0), y_{p}(t=0)$ and $x(t=0)$. Then oil starts to drain from orifice $O$, until the summation of air pressure inside $\mathrm{R}$ and $x(t) \rho g$ equals atmospheric air pressure. This is so even $q=0$. if the time period between start and cessation of oil flow for a given initial oil volume could be calibrated by using another time measuring method, eth pahana could be used as a time measuring device 
also. This suggests by placing different amount of oil in container $\mathrm{C}$, different time durations for oil flow could be obtained and by using a calibration system, the duration of flow could be standardized for time measurement, enabling the usage of eth pahana as a time measuring device.

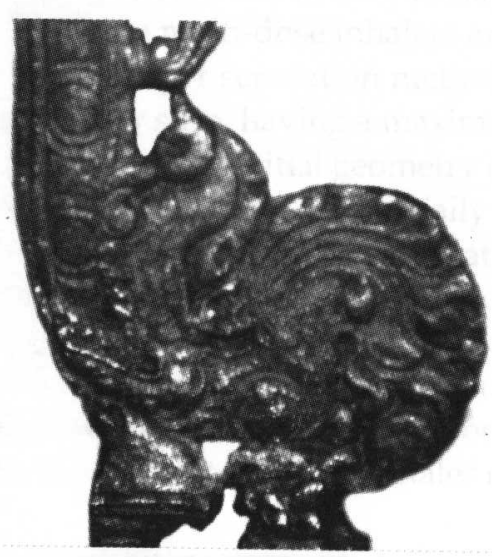

Fig. 5: Makara heads of eth pahana

As indicated in the construction features, the flame creeper ends with makara heads with their mouths open upwards. According to Wikramagamage [10], the makara figure symbolizes the time. Mahayana Buddhism expounds the belief that time will devour the bhutas [beings], and the makara thorana symbolizesthatconcept. Althoughthisconceptual interpretation alone does not qualify the assigning of eth pahana as a time measurement devise, the portraying of contemporary concepts in products with religious significance could not be ruled out. Therefore there is a possibility that eth pahana would have been used as a time measuring device also. The same set of equations could be used for this application also, with $\mathrm{q}=0$.

\section{Artistic Significance}

Without doubt, this is a product of exquisite workmanship which reveals the skill, the aesthetic judgment as well as the sense of humour of its originator. This represents a remarkable combination in the craftsmanship of not only a masterly grasp of techniques of metallurgy and knowledge of fluid behavior inside the tubes, but also of a superb aesthetic judgment with well proportioned scales and dimensions.

\section{Conclusion}

The prime intention of this paper was to formulate a scientific explanation on the operation of eth pahana. This was through a hypothetical sketch of internal structure and using equations for oil flow through orifice $\mathrm{O}$ and air pressure for the air volume trapped inside reservoir, R. Secondary to that objective, the functionality of eth pahana as a time measuring devise was also considered. It was shown that the automatic flow lock mechanism available with this devise makes it possible to use for calibrated time measurement, contrary to absolute time measurements offered by many ancient types of water clocks. What ever the functionality it would have fulfilled, it is noteworthy that the usage of natural phenomena in fulfilling human requirements, a common feature in our ancient technology, had been again utilized in designing this device.

\section{Acknowledgement}

Authors would like to extend their gratitude towards the cooperation received from $\mathrm{Mr}$. Ranjith Hewage, Director, Colombo National Museum and associated staff in collecting information and taking photographs of the eth pahana.

\section{References}

1. Pieris, K, Narayana, M, Wijesingha, S (2008), Ecosystem Based Indigenous Water Management, National Science Foundation, Colombo.

2. Paranavithana, S(2001), Puravidhu Paryesana, $2^{\text {nd }}$ print, Visidinu Publishers, Boralesgamuwa.

3. Gunawardana, R. A. L. H (1983), Ethno-Science and Technology in Pre-Colonial Sri Lanka, The Journal of the Sri Lanka National Archives, Vol. 1, No. 1, The Department of National Archives, Colombo.

4. Coomaraswamy, A. K (1914), Momoirs of the Colombo Museum, Series A, No.1, Bronzes from Ceylon, Chiefly in the Colombo Museum, Colombo Museum, Colombo.

5. Godakumbura, C. E (1964), Polonnaruwa Bronzes, Arts Series No.5, Archeological Department, Colombo. 
6. Rao, T. A. G (1914), Elements of Hindu Iconography, Vol. II, Part II, Madras.

7. Basham, A. L (1967), The Wonder that was India, Sidgwick \& Jackson, London.

8. Cotterell, B \& Kaminga, J (1990), Mechanics of Pre Industrial Technology, University of Cambridge, U.K.

9. Gorokov, V (1987), Engineering Art and Science, Mir Publishers, Moscow.

10. Wikramagamage, C (2000), Galvihara, Polonnaruwa - A Rare Creation by Human Hand, Academy of Sri Lankan Culture, Mattegoda 